\title{
Enhancing Cannabinoid Neurotransmission Augments the Extinction of Conditioned Fear
}

\author{
Jasmeer P Chhatwal', Michael Davis', Kimberly A Maguschak' and Kerry J Ressler*,I \\ 'Emory University School of Medicine, Department of Psychiatry and Behavioral Sciences, Center for Behavioral Neuroscience, Yerkes Research \\ Center, Atlanta, GA, USA
}

\begin{abstract}
The endogenous cannabinoid (eCB) system represents a major therapeutic target for the treatment of a variety of anxiety-related disorders. A recent study has demonstrated that pharmacologic or genetic disruption of CBI-receptor-mediated neurotransmission decreases the extinction of conditioned fear in mice. Here, we examined whether CBI blockade would similarly disrupt extinction in rats, using fear-potentiated startle as a measure of conditioned fear. We also examined whether pharmacologic enhancement of CBI activation would lead to enhancements in extinction. Our results indicate that systemic administration of the CBI antagonist rimonabant (SRI4I7I6A) prior to extinction training led to significant, dose-dependent decreases in extinction. While the administration of the CBI agonist WIN 55,2 I2-2 did not appear to affect extinction, administration of AM404, an inhibitor of eCB breakdown and reuptake, led to dose-dependent enhancements in extinction. In addition to showing decreased fear I and $24 \mathrm{~h}$ after extinction training, AM404-treated animals showed decreased shock-induced reinstatement of fear. Control experiments demonstrated that the effects of AM404 could not be attributed to alterations in the expression of conditioned fear, locomotion, shock reactivity, or baseline startle, as these parameters seemed unchanged by AM404. Furthermore, coadministration of rimonabant with AM404 blocked this enhancement of extinction, suggesting that AM404 was acting to increase CBI receptor activation during extinction training. These results demonstrate that the eCB system can be modulated to enhance emotional learning, and suggest that eCB modulators may be therapeutically useful as adjuncts for exposure-based psychotherapies such as those used to treat Post-Traumatic Stress Disorder and other anxiety disorders.

Neuropsychopharmacology (2005) 30, 516-524, advance online publication, 22 December 2004; doi: I 0. I 038/sj.npp. I 300655
\end{abstract}

Keywords: amygdala; fear; extinction; PTSD; cannabinoid; phobia

\section{INTRODUCTION}

Manipulation of the endogenous cannabinoid (eCB) system has become a major focus of current research, especially in the search for novel therapeutics to treat many common mental illnesses, including anxiety disorders, depression, and drug addiction (Porter and Felder, 2001; Kathuria et al, 2003). Indeed, the potential therapeutic value of cannabinoid modulation is underscored by the dense expression of the CB1 receptor in regions known to be important for anxiety and emotional learning, including the amygdala, hippocampus, and throughout the mesolimbic dopamine reward system (Katona et al, 1999, 2000, 2001; Freund et al, 2003; van der Stelt and Di Marzo, 2003).

*Correspondence: Dr KJ Ressler, Department of Psychiatry and Behavioral Sciences, Emory University, Yerkes Research Center, 954 Gatewood Dr., Atlanta, GA 30329, USA, Tel: + 404727 7739, Fax: 404727 8070, E-mail: kressle@emory.edu

Received 28 September 2004; revised 12 November 2004; accepted I 5 November 2004

Online Publication: 17 November 2004 at http://www.acnp.org/ citations/NPPI | | 704040460/default.pdf
Recent studies of CB1 knockout mice have demonstrated that the genetic deletion of the CB1 receptor leads to increased anxiety in several well-studied measures (Haller et al, 2002, 2004a, b; Martin et al, 2002). Furthermore, the elegant studies of Marsicano et al (2002) have demonstrated that CB1 knockout mice also show profound deficits in the learned inhibition of fear (heretofore referred to as extinction), while the acquisition of the initial fear response was normal. In the same study, the authors demonstrated that pharmacologic blockade of the CB1 receptor led to a similar deficit in extinction in mice, demonstrating the importance of $\mathrm{CB} 1$ receptor activation for extinction in mice.

The critical involvement of cannabinoid-mediated transmission in extinction potentially has important clinical implications, as numerous similarities link the expression of fear and anxiety in humans suffering from phobias, PostTraumatic Stress Disorder (PTSD), and other anxiety disorders to the expression of classically conditioned fear in animals. Perhaps the most important of these similarities is the persistence of fear memories in both humans and animal models. In this context, studying extinction in animals may further the development of experimental 
therapeutics for the treatment of these disorders. Indeed, recent results from our laboratory have shown that the administration of a partial NMDA agonist both enhances the extinction of conditioned fear in rodents (Walker et al, 2002), and can increase the efficacy of behavioral exposure therapy in human phobics (Ressler et al, 2004).

Furthermore, several recent studies have suggested that prolonging the action of released cannabinoids through the inhibition of the enzyme fatty-acid amide hydrolase (FAAH), which is critically involved in cannabinoid catabolism and reuptake, leads to anxiolysis in rodents (Kathuria et al, 2003). The results of these and other studies have highlighted the sizable potential of the $\mathrm{CB} 1$ receptor and the eCB-degradative enzyme FAAH as targets of experimental therapeutics (eg Porter and Felder, 2001; Kathuria et al, 2003).

Given the mounting clinical interest in modulators of the eCB system, we examined whether the CB1 antagonist rimonabant (SR141716A) would block extinction of fear in rats as measured with fear-potentiated startle. We then examined if administration of an agonist (WIN 55,212-2) or of an inhibitor of eCB reuptake and breakdown (AM404) would enhance the extinction of conditioned fear. In so doing, we addressed whether manipulation of the eCB system could lead to enhancements as well as decrements in extinction, a clinically relevant form of fear modulation important in the understanding of emotional learning and in the treatment of anxiety-related behaviors.

\section{MATERIALS AND METHODS}

\section{Animals}

The procedures used were approved by the Institutional Animal Care and Use Committee of Emory University and in compliance with National Institutes of Health (NIH) guidelines for the care and use of laboratory animals. A total of 216 adult male Sprague-Dawley rats (Charles River, Raleigh, NC) weighing between 350 and $450 \mathrm{~g}$ were used. Animals were housed in pairs in a temperature-controlled $\left(24^{\circ} \mathrm{C}\right)$ animal colony, with ad libitum access to food and water. They were maintained on a $12 \mathrm{~h}$ light/dark cycle with lights on at 0800 , with all behavioral procedures performed during the rats' light cycle.

\section{In Situ Hybridization}

In situ hybridization was performed as previously described (Ressler et al, 2002). A cDNA clone containing the coding sequence of the rat cannabinoid receptor type 1 (CB1) (I.M.A.G.E. expressed sequence tag clone, GI Accession \#11375084) was linearized after sequence verification. An antisense riboprobe was generated with T3 RNA polymerase. Slide-mounted sections of snap-frozen rodent brain tissue were postfixed, proteinase $\mathrm{K}$ digested, blocked, and hybridized overnight at $52^{\circ} \mathrm{C}$ with ${ }^{35} \mathrm{~S}$-UTP-labeled riboprobes. After a stringent wash protocol, slides were apposed to autoradiography film and hybridization density was qualitatively assessed.

\section{Fear Conditioning}

Animals were trained and tested in $8 \times 15 \times 15 \mathrm{~cm}$ Plexiglas and wire-mesh cages, with floors consisting of four $6.0-\mathrm{mm}$ diameter stainless-steel bars spaced $18 \mathrm{~mm}$ apart. Each cage was suspended between compression springs within a steel frame and located within a custom-designed $90 \times 70 \times 70 \mathrm{~cm}$ ventilated sound-attenuating chamber. Background noise (60-dB wide-band) was provided by a General Radio Type 1390-B noise generator (Concord, MA) and delivered through high-frequency speakers (Radio Shack Supertweeter; Tandy, Fort Worth, TX) located $5 \mathrm{~cm}$ from the front of each cage. Sound level measurements (sound pressure level) were made with a Bruel \& Kjaer (Marlborough, MA) model 2235 sound-level meter (A scale; random input) with the microphone (Type 4176) located $7 \mathrm{~cm}$ from the center of the speaker (approximating the distance of the rat's ear from the speaker). Startle responses were evoked by 50-ms, 95- $\mathrm{dB}$ white-noise bursts generated by a Macintosh G3 computer soundfile $(0-22 \mathrm{kHz})$, amplified by a Radio Shack amplifier (100 W; model MPA-200; Tandy), and delivered through the same speakers used to provide background noise. An accelerometer (model U321AO2; PCB Piezotronics, Depew, NY) affixed to the bottom of each cage produced a voltage output proportional to the velocity of cage movement. This output was amplified (model 483B21; PCB Piezotronics) and digitized on a scale of $0-2500 \mathrm{U}$ by an InstruNET device (model 100B; GW Instruments, Somerville, MA) interfaced to a Macintosh G3 computer. Startle amplitude was defined as the maximal peak-to-peak voltage that occurred during the first $200 \mathrm{~ms}$ after onset of the startle-eliciting stimulus. The CS was a 3.7-s light (82 lux) produced by an $8 \mathrm{~W}$ fluorescent bulb $(100 \mu \mathrm{s}$ rise time) located $10 \mathrm{~cm}$ behind each cage. Luminosity was measured using a VWR light meter (Atlanta, GA). The US was a 0.5-s shock, delivered to the floorbars and produced by a shock generator (SGS-004; Lehigh Valley, Beltsville, MD). Shock intensities (measured as in Cassella and Davis, 1986) were $0.4 \mathrm{~mA}$. The presentation and sequencing of all stimuli were under the control of the Macintosh G3 computer using custom-designed software (The Experimenter; Glassbeads Inc., Newton, CT). Animals were pre-exposed to the chambers for $10 \mathrm{~min}$ on each of 2 days prior to training to habituate them to handling and the test chambers and to minimize the effects of contextual conditioning. On 2 consecutive days following habituation, rats were returned to the same chambers and presented with 10 pairings of a light $(3.7 \mathrm{~s})$ coterminating with a $0.4-\mathrm{mA}, 0.5$-s shock (3.6-min intertrial interval).

\section{Matching}

At $24 \mathrm{~h}$ following the last fear-conditioning session, animals were returned to the same chambers and presented with startle stimuli (50-ms, $95-\mathrm{dB}$ white-noise bursts) in the presence or absence of the light-conditioned stimulus (15 light-startle compounds and 15 startle alone). Increased startle in the presence of the light-CS was taken as a measure of conditioned fear, and the magnitude of the fear response was calculated as the percentage by which startle increased when the light-CS was presented in compound with the startle stimulus $v s$ when it was omitted (fear- 
potentiated startle or FPS). Using these measurements, animals were divided into groups displaying approximately equal levels of FPS prior to drug treatment and extinction training.

\section{Extinction Training}

At 5 days following the last fear-conditioning trial, animals were injected intraperitoneally with a test compound or its vehicle in $1 \mathrm{ml} / \mathrm{kg}$ volumes and then immediately returned to the same chambers and presented with 30 or 90 presentations of the light-CS in the absence of footshock (3.7-s light, 30-s intertrial interval). At $1 \mathrm{~h}$ following this extinction training session, animals were given a short test consisting of startle stimuli in the presence or absence of the light-CS (2-5 light-startle compounds and 2-5 startle alone, values shown are averages of all trials). At $24 \mathrm{~h}$ postextinction training, all animals were tested for the presence of fear-potentiated startle (15 light-startle compounds and 15 startle alone). As animals showed a large amount of extinction within the 24 -h testing session (within-session extinction), the FPS values shown for all drug studies are the average FPS during the first five light-startle compounds.

\section{Reinstatement}

Previously fear-conditioned and extinction-trained animals were returned to the testing chamber $48 \mathrm{~h}$ following extinction training and presented with three footshocks in the absence of the light-CS $(0.4 \mathrm{~mA}, 0.5 \mathrm{~s}$ shock, 2 min intertrial interval). Immediately following the unpaired shocks, animals were tested for the presence of fearpotentiated startle (15 light-startle compounds, and 15 startle alone).

\section{Shock Reactivity, Startle, and Activity Measures}

A separate group of fear-conditioned animals was injected with AM404, placed in the training/testing chambers, and presented with three unpaired shocks and 42 startle stimuli (0.4-mA, 0.5-s shocks, 95-dB noise-burst startle). The same group of animals was returned to the same chambers 3 days later, injected with vehicle, and presented with an identical behavioral test. The values shown are the mean integrated voltages of the accelerometers measured over 200-ms periods beginning at the onset of either the shocks or the startle stimuli. Additionally, a measure of spontaneous motor activity was derived from the mean displacement of the accelerometers in the $2 \mathrm{~min}$ prior to delivery of the first shock, while animals were exploring the chambers.

\section{Drugs}

Rimonabant (SR141716A, NIMH Drug Supply Program, Bethesda, MD) and WIN 55,212-2 (Biomol, Plymouth Meeting, PA) were dissolved in 100\% DMSO. AM404 (Biomol, Plymouth Meeting, PA) was dissolved in $70 \%$ DMSO, 30\% PBS. In experiments in which both rimonabant and AM404 were used, all drugs were dissolved in $100 \%$ DMSO.

\section{Statistics}

Comparisons were made across drug-treatment groups at each test (eg 24-h groups were compared across treatment groups) using ANOVA or Student's $t$-test with drug or dose as the independent measure, and using Fischer's LSD test for post hoc analysis.

\section{RESULTS}

\section{CB1 is Enriched in the Rat Basolateral Amygdala (BLA)}

The BLA has been repeatedly implicated in the extinction of conditioned fear in both direct pharmacological inactivation and augmentation studies (Falls et al, 1992; Walker et al, 2002; Davis et al, 2003). In situ hybridization was used to determine if $\mathrm{CB} 1 \mathrm{mRNA}$ was expressed within the rat amygdala and whether it was differentially expressed in the basolateral, medial, and central amygdaloid nuclei. Representative sections from these in situ hybridization studies (Figure 1), suggest that CB1 mRNA is highly enriched in the BLA, with very little CB1 mRNA expression seen in the central (CeA) or medial nuclei (MeA) of the amygdala. Additionally, the presence of the mRNA for the CB1 protein within the BLA itself suggests that the CB1-mediated signaling taking place in the BLA is part of the intrinsic neurocircuitry of the BLA. These hybridization results are in close agreement with previous studies using immunohistochemical and hybridization techniques (Katona et al, 1999; Marsicano and Lutz, 1999; McDonald and Mascagni, 2001).

\section{CB1 Antagonist Blocks Extinction}

The next experiment examined whether pharmacologic antagonism of the $\mathrm{CB} 1$ receptor would disrupt extinction in rats and the dose-response relationship for this interaction. Parametric studies were performed to identify a set of behavioral manipulations that could reliably induce extinction in rats. In these studies (outlined in Figure 2a), animals
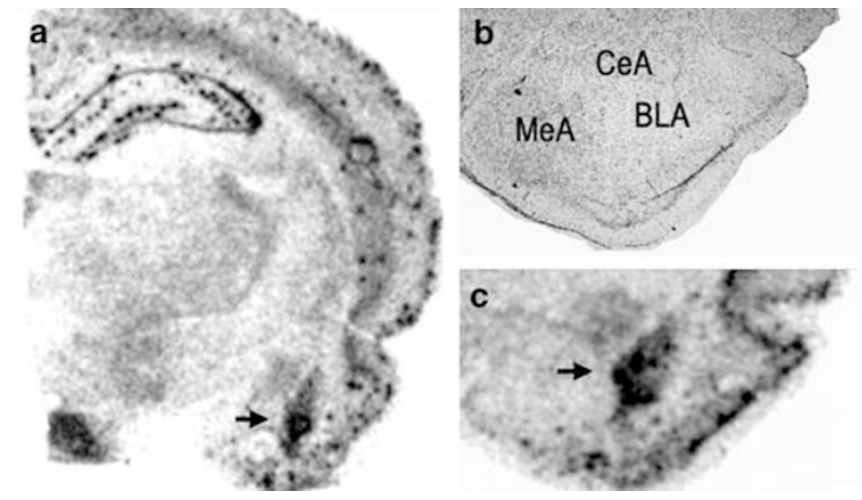

Figure I $\mathrm{CBI}$ is densely expressed within rat BLA. Expression patterns of CBI-receptor mRNA are shown following in situ hybridization with a ${ }^{35}$ S-labeled antisense riboprobe. (a) Dense CBI mRNA expression is seen within amygdala (arrow) and hypothalamus, with more sparse cellular expression throughout hippocampus and cortex. (b) Cresyl violet-stained sections of the temporal lobe. (c) CBI is most densely expressed within the basolateral amygdala (BLA, arrow). CeA = central amygdaloid nucleus, $\mathrm{MeA}=$ medial amygdaloid nucleus. 
a

Fear Acquisition X 2d
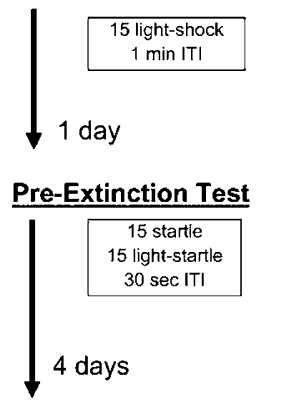

\section{Extinction}

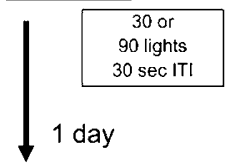

Post-Ext Test

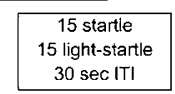

b
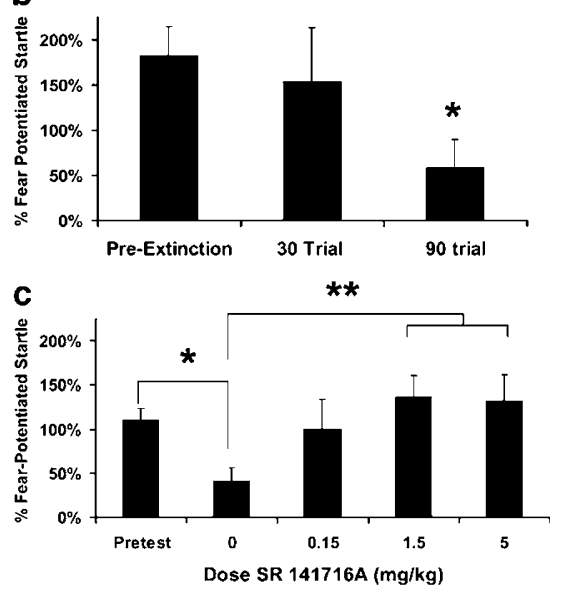

d

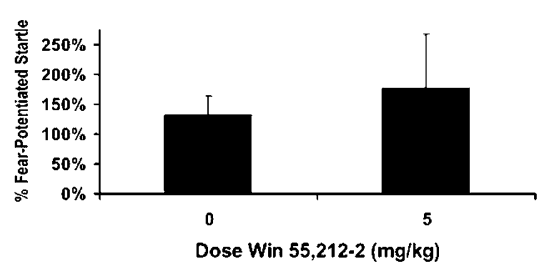

Figure 2 Effect of CBI antagonist on extinction of fear. (a) Timeline for behavioral experiments. (b) Percent fear-potentiated startle (\% FPS) $24 \mathrm{~h}$ following extinction training (lights without shocks). Animals receiving 90 light exposures showed significant extinction compared to pretest. (c) \% FPS is shown for the pre-extinction test and $24 \mathrm{~h}$ postextinction tests of four groups of animals that received SR $141716 \mathrm{~A}(0,0.15,1.5,5 \mathrm{mg} / \mathrm{kg}$, i.p.) prior to extinction training ( $n=16$ for $0,1.5$, and $5 \mathrm{mg} / \mathrm{kg}$ groups; $n=8$ for $0.15 \mathrm{mg} / \mathrm{kg}$ group). Only the vehicle group $(0 \mathrm{mg} / \mathrm{kg})$ demonstrated significant extinction to the light, and animals receiving the two higher doses of rimonabant displayed significantly greater \% FPS than vehicletreated controls (*denotes $p<0.05$, ** denotes $p<0.0$ I). (d) \% FPS following extinction in the presence of the CBI agonist, WIN 55,2 I2-2 ( $n=5$ per group).

showed robust fear conditioning prior to extinction training and varying the number of nonreinforced light-CS presentations decreased the amount of fear animals showed in subsequent testing trials (Figure $2 \mathrm{~b}$ ). We found that 90 trials of nonreinforced lights led to significant extinction retention, whereas only 30 trials led to a more modest, nonsignificant reduction in fear (compared to pre-extinction: 90 trials, $\mathrm{F}_{(1,27)}=4.05, p<0.05 ; 30$ trials, $\left.p>0.05\right)$. In all subsequent studies, the 90 -trial extinction protocol was used when trying to block extinction, while the weaker 30trial extinction protocol was used when trying to enhance extinction.

This 90-trial extinction protocol was used to test the effect of systemic administration of the CB1 antagonist rimonabant on extinction in rats. The acute administration of rimonabant to rats immediately prior to extinction training led to a profound disruption of extinction retention, as evidenced by the fact that rimonabant-treated animals showed significantly higher levels of fear in the presence of the light-CS $24 \mathrm{~h}$ following extinction training (Figure 2c, ANOVA dose $\times$ postextinction FPS, $\left.\mathrm{F}_{(3,55)}=3.40, p<0.05\right)$. This disruption in extinction appeared to be dosedependent, as animals receiving 1.5 or $5 \mathrm{mg} / \mathrm{kg}$ of rimonabant showed significantly higher levels of conditioned fear

than vehicle-treated controls, and appeared to show virtually no reduction in conditioned fear following extinction training (post hoc, $p<0.01$ for 1.5 and $5 \mathrm{mg} / \mathrm{kg}$ compared to vehicle). The ability of rimonabant to disrupt extinction at the relatively low doses used here suggested that the neural process underlying extinction may be extremely sensitive to the level of $\mathrm{CB} 1$ receptor activation during extinction training.

\section{A Direct CB1 Agonist has No Effect on Extinction}

The next experiment examined whether the application of the CB1 direct agonist WIN 55-212,2 (WIN) prior to extinction training might enhance extinction retention. A relatively high dose of WIN $(5 \mathrm{mg} / \mathrm{kg})$ was administered prior to a 30 trial-extinction training protocol, to determine if increasing CB1 activation would augment the modest extinction normally induced by this weak training protocol. The administration of $5 \mathrm{mg} / \mathrm{kg}$ WIN prior to extinction training did not enhance extinction; in contrast, WINtreated animals actually showed a nonsignificant, but slightly higher, level of conditioned fear $24 \mathrm{~h}$ following extinction training (Figure 2d). Notably, the well-documented emergence of prominent locomotor and analgesic effects following administration of higher doses of WIN (eg Tsou et al, 1996; Herzberg et al, 1997) limited our ability to test the effects of doses of WIN greater than $5 \mathrm{mg} / \mathrm{kg}$.

One explanation for this lack of agonist effect on extinction is that the CB1 receptor could be rapidly downregulated following direct agonist administration (Coutts et al, 2001; Hsieh et al, 1999). The next experiments examined whether augmentation of endogenously released eCBs, instead of direct agonist administration, would have a different effect.

\section{AM404, an Inhibitor of Cannabinoid Reuptake and Breakdown, Enhances Extinction}

In contrast to the potential compensatory decrease in efficacy of CB1-mediated transmission following direct agonist administration, an inhibitor of $\mathrm{eCB}$ reuptake or breakdown may enhance extinction by prolonging the action of released eCBs. This, in turn, would lead to increases in activity-dependent CB1-receptor activation.

Consistent with this hypothesis, administration of AM404 prior to 30-trial extinction training led to an enhancement of extinction retention, as AM404 animals showed significantly less fear in the presence of the CS $24 \mathrm{~h}$ following extinction training (Figure 3a, main effect of drug treatment $\left.\mathrm{F}_{(1,70)}=4.06, p<0.05\right)$. This enhancement of extinction appeared to be dose-dependent, as animals treated with $10 \mathrm{mg} / \mathrm{kg}$ AM404 showed less fear than those treated with $2 \mathrm{mg}$ AM404 and significantly less than vehicle-treated animals (10 mg vs control, post hoc $p<0.05$ ).

A subset of AM404-treated animals was tested $1 \mathrm{~h}$ following extinction to assess whether the effects of AM404 were likely taking place during the acquisition phase of extinction. The AM404-induced enhancement of extinction was evident $1 \mathrm{~h}$ postextinction, as animals that received the $10-\mathrm{mg} / \mathrm{kg}$ dose of AM404 showed significantly less fear than vehicle-treated controls (Figure 3b, ANOVA 


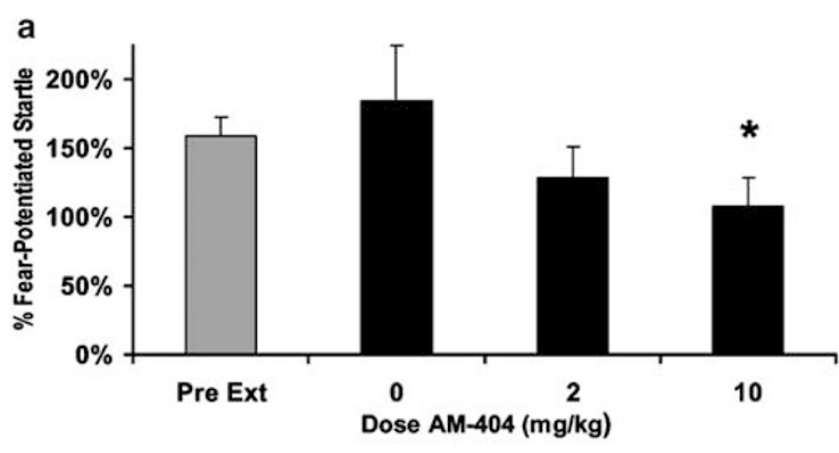

b
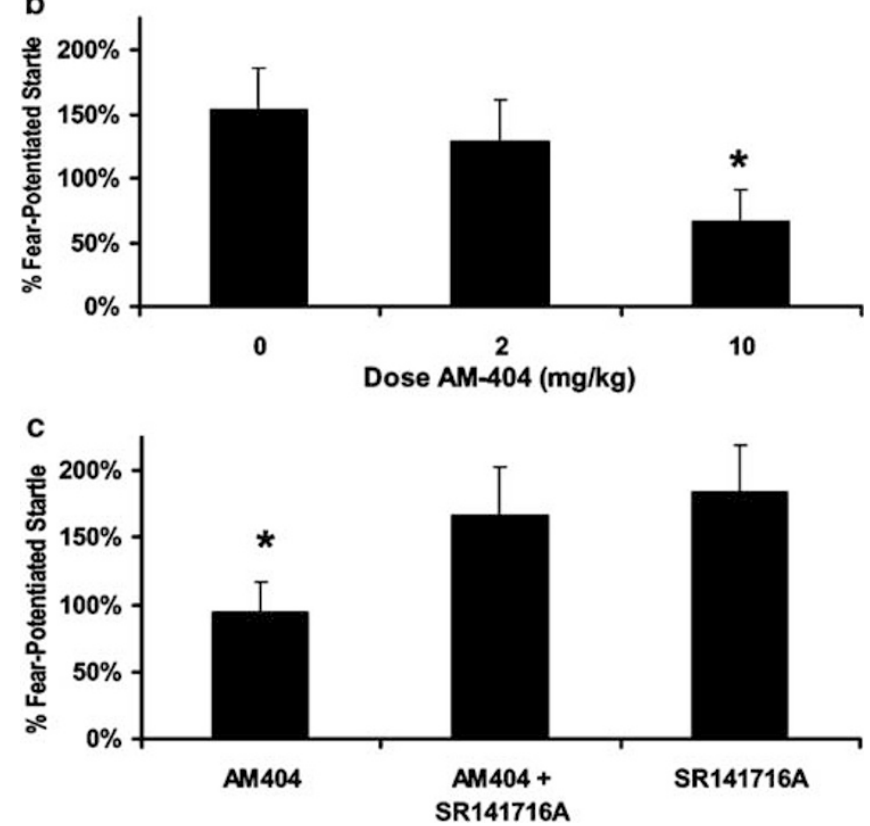

Figure 3 CBI reuptake inhibitor enhances extinction. AM404 was given prior to extinction training in rats previously fear conditioned as in Figure 2a. (a) \% FPS during $24 \mathrm{~h}$ postextinction testing in animals that received 0 , 2 , or $10 \mathrm{mg} / \mathrm{kg}$ AM404, i.p., prior to extinction training $(n=21$ for 0 and $2 \mathrm{mg} / \mathrm{kg}$; $n=29$ for $10 \mathrm{mg} / \mathrm{kg}$ ). These data demonstrate increasing extinction (decrement in \% FPS) with increasing doses of AM404. (b) \% FPS during I h postextinction testing in animals that received 0,2 , or $10 \mathrm{mg} / \mathrm{kg}$ AM404, i.p., prior to extinction training $(n=13$ for 0 and $10 \mathrm{mg} / \mathrm{kg}, n=12$ for $2 \mathrm{mg} /$ $\mathrm{kg}$ ). (c) \% FPS during $24 \mathrm{~h}$ postextinction testing in animals that received $10 \mathrm{mg} / \mathrm{kg}$ AM404 i.p., $5 \mathrm{mg} / \mathrm{kg}$ rimonabant i.p., or the combination prior to extinction training ( $n=8$ per group), demonstrating that coadministration of a $\mathrm{CBI}$ antagonist prevented AM404 from enhancing extinction. (*denotes $p<0.05$ )

linear contrast $\mathrm{F}_{(1,37)}=4.89, p<0.05$; post hoc comparison, $10 \mathrm{mg} / \mathrm{kg} v s$ vehicle, $p<0.05)$.

\section{AM404-Dependent Enhancement of Extinction Appears to be Mediated by Activation of CB1 Receptor}

AM404 has been implicated in the inhibition of eCB reuptake as well as in inhibiting FAAH (Jarrahian et al, 2000; Beltramo et al, 2000; Giuffrida et al, 2001), but does not itself activate CB1 receptors (eg Beltramo et al, 1997). As the enzyme FAAH participates in the breakdown of a number of neuroactive arachidonic-acid derivates (Giuffrida et al, 2001) and some have suggested that AM404 may also act at the vanilloid receptor (VR1, Smart and Jerman,
2000), a series of experiments was performed to determine if the AM404-induced enhancement of extinction requires CB1 activation.

Animals were fear conditioned and extinction trained (30 trial extinction) as in the previous study, and prior to extinction training administered $10 \mathrm{mg} / \mathrm{kg}$ AM404, $10 \mathrm{mg} / \mathrm{kg}$ $\mathrm{AM} 404+5 \mathrm{mg} / \mathrm{kg}$ rimonabant, or $5 \mathrm{mg} / \mathrm{kg}$ rimonabant alone. During testing, animals administered AM404+ rimonabant and rimonabant alone showed virtually no decrease in FPS $24 \mathrm{~h}$ following extinction. In contrast, animals treated with $10 \mathrm{mg} / \mathrm{kg}$ AM404 alone showed significant extinction $\left(t_{(26)}=2.36, p<0.05\right.$ AM404 alone as compared to pre-extinction), and significantly less fear than animals receiving $\mathrm{AM} 404$ + rimonabant or rimonabant alone (Figure $3 c, F_{(1,23)}=5.40, p<0.05$, rimonabant and rimonabant + AM404 groups pooled for comparison). Taken together, these results suggest that the enhancement of extinction seen in AM404-treated animals is mediated via CB1-receptor activation.

\section{AM404-Induced Enhancement of Extinction Requires Cue-Exposure and is not Due to Drug-Induced Changes in the Expression of Conditioned Fear}

A series of control experiments was performed to rule out the possibility that AM404 administration itself could lead to decreases in the expression of conditioned fear, even in the absence of cue re-exposure during extinction training. To this end, a parallel set of rats was fear conditioned and matched for equivalent levels of FPS as in the above studies. On the day on which extinction training was to be performed, animals were administered $10 \mathrm{mg} / \mathrm{kg}$ AM404, $5 \mathrm{mg} / \mathrm{kg}$ rimonabant, or vehicle, but cue re-exposure was omitted. At $1 \mathrm{~h}$ following drug administration, animals were tested for FPS using a procedure similar to the above studies. The results from these studies indicate that the highest doses of AM404 and rimonabant used here had no effect on FPS if cue-exposure was omitted, as all drug groups showed similar levels of conditioned fear $1 \mathrm{~h}$ following drug administration (Figure 4a).

\section{AM404 Treatment Does not Lead to Obvious Analgesic or Locomotor Effects}

To better understand the behavioral effects engendered by AM404 treatment, a series of control experiments was performed. These included testing the effects of $10 \mathrm{mg} / \mathrm{kg}$ AM404 on (1) shock reactivity as a measure of pain sensitivity, (2) baseline startle as one measure of anxiety, and (3) general motor activity within the training chambers. Animals were fear conditioned and then returned to the training chamber several days later and administered $10 \mathrm{mg} / \mathrm{kg}$ AM404. Following drug administration, animals were presented with three shocks and 42 startle stimuli identical to those used in the above studies. Subsequently, the same animals were returned to the testing chamber 3 days later, injected with vehicle, and similarly tested. The results from these studies (Figures $4 \mathrm{~b}-\mathrm{d}$ ) showed that the administration of AM404 had little effect on shock reactivity or overall locomotor activity levels in the testing chamber ( $p>0.5$ for both comparisons). The apparent decrease in baseline startle observed following AM404 administration 

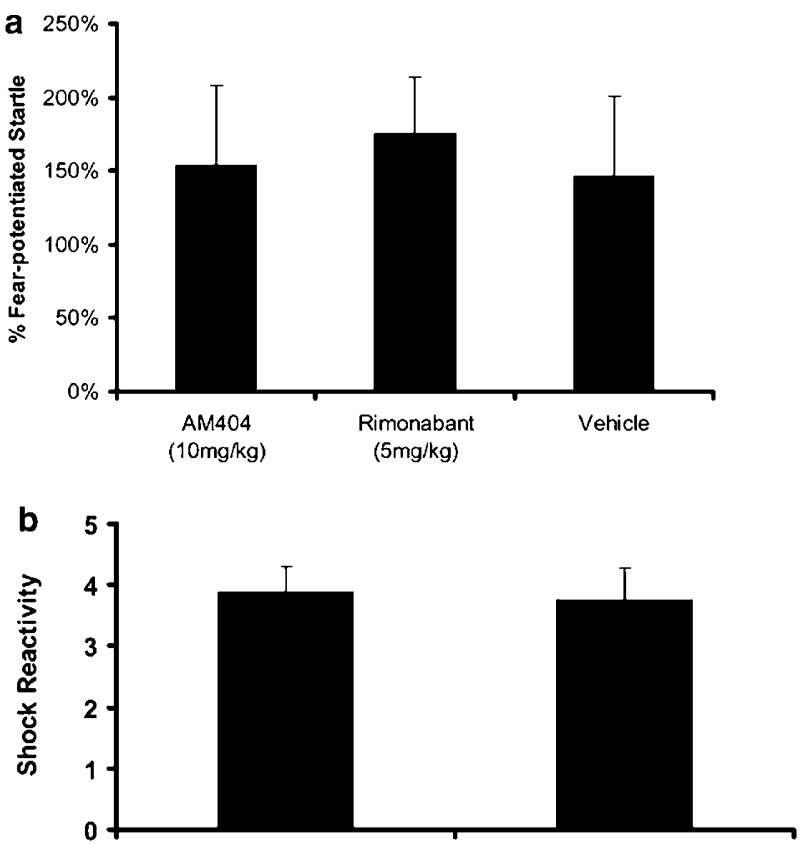

0

10
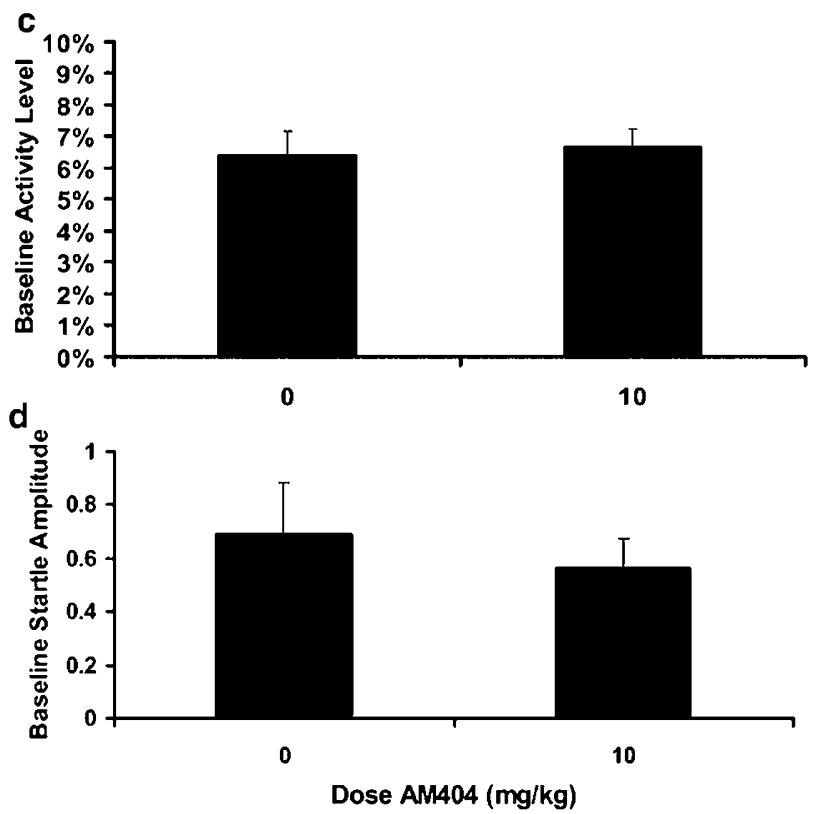

Figure 4 AM404 effect on extinction is independent of effects on the expression of conditioned fear, pain, locomotion, and baseline anxiety. (a) Animals fear-conditioned as in the above studies were administered AM404 (I0 mg/kg), rimonabant (SRI4I7I6A, $5 \mathrm{mg} / \mathrm{kg})$, or vehicle and I h later tested for FPS (cue re-exposure was omitted, $n=8$ per group). Neither AM404 nor rimonabant treatment led to significant alterations in the expression of conditioned fear when cue re-exposure was omitted. (b) Average shock reactivity is shown in arbitrary units and represents the average response to three footshocks. (c) Average baseline activity level is shown in arbitrary units as determined by mean displacement of accelerometers during the 2 min prior to the delivery of any shocks in the test chambers. (d) Average baseline startle amplitude shown in arbitrary units during the presentations of startle stimuli $(n=8$ per group for $b-d)$.

was not significant $(p=0.45)$. Taken together, these results suggest that the administration of AM404 at the doses used in this study are insufficient to generate obvious motor or analgesic effects, and do not likely affect anxiety levels as measured by baseline startle amplitude.

\section{AM404 Treatment Prior to Extinction Training Decreases Shock-Induced Reinstatement of Fear}

Shock-induced reinstatement was then examined 2 days following treatment with AM404 or vehicle during extinction. Previous studies have shown that the level of fear following reinstatement is dependent both on the level of the stressor and the amount of previous extinction, as long as the stressor is delivered in the same context as the original training context (Rescorla and Heth, 1975; Bouton and King, 1983). Thus, diminished reinstatement following extinction serves as an additional measure of the strength of the extinction process. As animals were matched for equivalent FPS prior to extinction training, the susceptibility of animals to reinstatement can be taken as a secondary measure of the strength of extinction training, and perhaps as a preliminary measure of the resiliency of these inhibitory extinction memories to stressors.

In these studies, animals that had previously been fear conditioned, extinction trained, and tested for extinction retention were returned to the training chambers and presented with three footshocks (in the absence of light-CS presentation) followed by a test for the presence of FPS to the light-CS. During these reinstatement tests, AM404treated animals showed less reinstatement-induced conditioned fear, whereas control animals showed a transient but robust re-emergence of conditioned fear following the unpaired footshocks. This effect was especially prominent during the first two testing trials, where vehicle-treated animals showed significantly more fear to the light CS than their AM404-treated counterparts (Figure 5a $t_{(63)}=4.5$, $p<0.05,2$ and $10 \mathrm{mg} / \mathrm{kg}$ AM404-treated groups pooled for comparison to vehicle). Additionally, examination of within-session extinction demonstrated a significant decrease in FPS among vehicle-treated groups, but little change among AM404-treated groups (Figure 5b, repeated measures ANOVA, Trial $\times$ Drug interaction, $\left.F_{(1,62)}=5.67, p<0.02\right)$. Note that within this period of extinction testing, neither group reached terminal levels of extinction.

\section{DISCUSSION}

These experiments demonstrate that: (1) CB1 mRNA is expressed densely and relatively specifically within the rat BLA, a region implicated in the extinction of conditioned fear, and there is little expression seen in the medial and central nuclei; (2) systemic application of a specific CB1 antagonist (SR 141716A) to rats dose-dependently blocks the extinction of fear as it does in mice; (3) this dosedependent blockade of extinction is robust and easily measured using fear-potentiated startle as a measure of fear; (4) systemic application of AM404, an inhibitor of eCB breakdown and membrane transport, dose-dependently enhances extinction of fear as measured at different times following cue re-exposure; (5) this enhancement of extinction is not likely due to changes in baseline anxiety, locomotion, or nociception; (6) the enhancement of extinction with AM404 is likely CB1-dependent, as this 

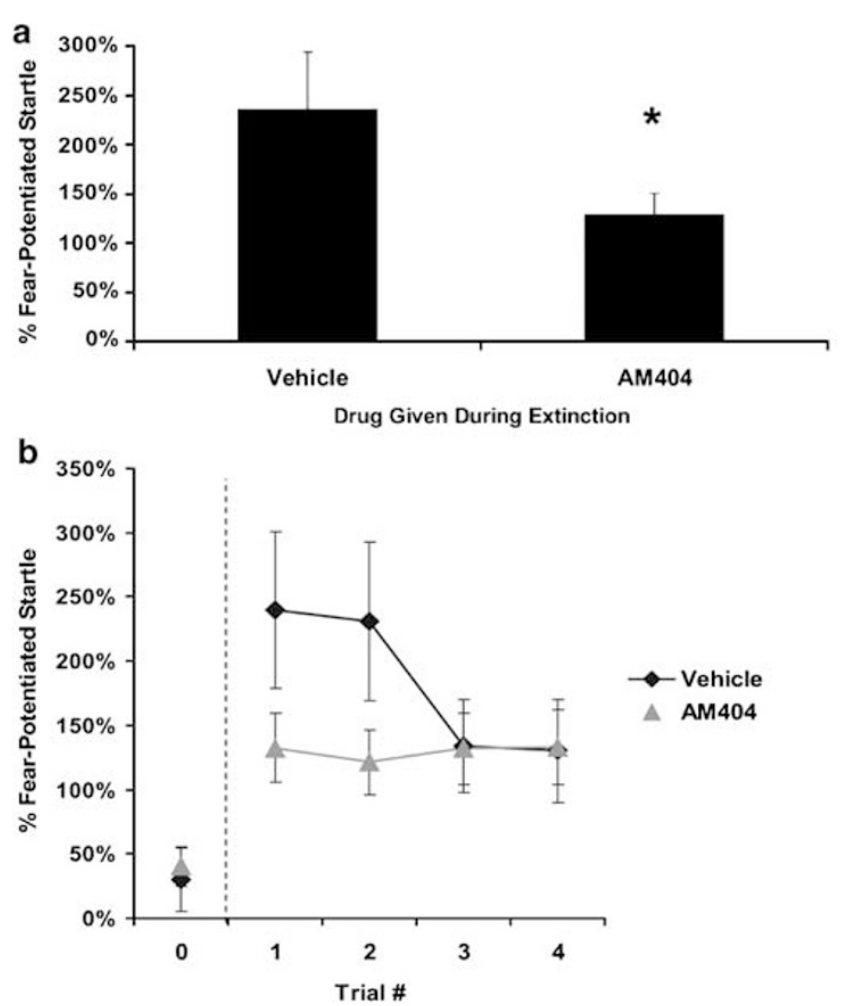

Figure 5 AM404-enhanced extinction decreases shock-induced reinstatement. (a) \% FPS is shown during testing following reinstatement with three footshocks. Animals had received vehicle $(n=21)$ or AM404 (2-mg and 10 -mg groups combined, $n=42$ ) prior to extinction training (ie, $48 \mathrm{~h}$ prior to reinstatement). Animals that received AM404 prior to extinction training demonstrated significantly less \% FPS following reinstatement than did control animals. (*denotes $p<0.05$ ) (b) Within-session extinction is shown for the first four trials during the testing of FPS following the reinstatement experiment described in (a). The terminal level of FPS in the last testing trial prior to reinstatement (shown as trial 0) indicates that vehicle and AM404-treated animals showed similar FPS levels prior to reinstatement.

effect is blocked almost completely by coadministration of rimonabant; and (7) this enhancement of extinction appears to diminish reinstatement of fear following footshock.

As has been shown previously, eCB function is normally required for extinction of fear in mice using both pharmacological (Marsicano et al, 2002; Suzuki et al, 2004) and genetic approaches in CB1 knockout animals (Marsicano et al, 2002). In this study, we demonstrate that blockade of the CB1 receptor with rimonabant also prevents extinction of fear in rats as measured with the fearpotentiated startle paradigm.

That a similar effect did not occur with systemic application of the direct CB1 agonist, WIN 55,212-2, could be due to a rapid downregulation or desensitization of the CB1 receptor following prolonged activation (Coutts et al, 2001; Hsieh et al, 1999). Direct CB1 agonists have been shown to lead to downregulation of CB1 receptors (Hsieh et al, 1999) and to uncoupling of the CB1 receptor from its effector G-protein, $\mathrm{G}_{\mathrm{i}}$ (Mato et al, 2004). The presence of a physiologic mechanism to rapidly decrease the efficacy of CB1-mediated transmission would have important implications for future and ongoing clinical studies examining the use of direct CB1 agonists for the treatment of anxiety disorders and drug addiction. Future studies examining a broader range of doses of WIN 55,212-2 would be necessary to definitely determine if a lower dose of this drug might enhance extinction without leading to potential CB1 downregulation. These concerns make the use of inhibitors of cannabinoid reuptake and of FAAH more clinically attractive, since the cannabinoid system has very low basal levels of activation (Giang and Cravatt, 1997; Cravatt $e t$ al, 2001).

Reinstatement of fear is one of the principle behavioral processes upon which the idea is based that extinction does not lead to an 'erasure' of memory, but rather to a parallel inhibitory process that masks the previous fear memory (for a review, see Myers and Davis, 2002). We found that animals that had received AM404 during the extinction exposure showed less initial fear-potentiated startle when tested following reinstatement in the absence of any drug (Figure $5 \mathrm{a}$ and $\mathrm{b}$ ). This finding is consistent with previous findings in which pharmacological enhancement of extinction with D-cycloserine (DCS) leads to less reinstatement (Ledgerwood et al, 2004), and provides further support for the hypothesis that the extinction seen following AM404 treatment is more robust and less susceptible to subsequent stress than the extinction seen in vehicle-treated controls. Future studies using more clinically relevant stressors and contexts are needed to clarify whether AM404 reduces susceptibility to reinstatement in a therapeutically useful way.

Drugs that can be given only at the time of extinction may provide for a new and powerful way to treat anxiety disorders. We and others have previously shown that extinction, which is known to be NMDA-dependent (Falls et al, 1992; Santini et al, 2001; Suzuki et al, 2004), can be enhanced with systemic or local administration into the amygdala of DCS, a partial NMDA agonist (Walker et al, 2002; Ledgerwood et al, 2003, 2004). Follow-up clinical trials have now demonstrated that this approach may be successful in humans as well (Ressler et al, 2004; Rothbaum and Davis, 2003).

AM404 and other inhibitors of the anandamide transporter, such as the newly identified AM1172 (Fegley et al, 2004), may enhance the process of extinction through an alternate mechanism. Since DCS can potentially activate all NMDA receptors, it is possible that it could enhance fear learning as well as extinction, although this has not been observed experimentally (Ledgerwood et al, 2003). In contrast, the CB1-receptor knockout mice have no decrement in fear learning, and pharmacological blockade of CB1 does not affect fear conditioning (Marsicano et al, 2002). Therefore, it appears that the activation of the cannabinoid system may be relatively specific to effects on inhibitory learning within the BLA, and it may not be required for or have a substantial impact on excitatory learning such as fear conditioning. This idea fits well with recent physiologic studies suggesting that $\mathrm{CB} 1$ activation may lead to enhanced LTD by presynaptically decreasing GABA release within the BLA (Azad et al, 2003; Chevaleyre and Castillo, 2003), perhaps via coincident activation of both presynaptic NMDA and cannabinoid receptors, as has been elegantly shown in the neocortex (Sjostrom et al, 2003). Lastly, it has been shown that extinction learning critically requires the activation of MAP kinase and calcineurin ( $\mathrm{Lu}$ et al, 2001; 
Lin et al, 2003a,b), and that CB1-receptor activation regulates the activity of a variety of kinases and phosphatases within the BLA (including MAP kinase and calcineurin, Cannich et al, 2004), providing a putative mechanistic link between eCB modulation and the plasticity underlying extinction.

Taken together, the findings in the present study suggest that augmenting eCB-mediated neurotransmission by inhibition of $\mathrm{eCB}$ transport or breakdown may provide a novel mechanism for enhancing the extinction of fear. As such, eCB reuptake inhibitors may serve as useful adjuncts in the treatment of anxiety disorders (such as PTSD, panic disorder, and OCD) as well as drug addiction and other disorders that respond to behavioral treatments utilizing extinction processes.

\section{ACKNOWLEDGEMENTS}

This study was supported by NIH (MH070218, JC, MH69884, KR, and MH47840, MD), and the Science and Technology Center Program (Center for Behavioral Neuroscience) of the National Science Foundation under Agreement IBN-987675.

\section{REFERENCES}

Azad SC, Eder M, Marsicano G, Lutz B, Zieglgansberger W, Rammes G (2003). Activation of the cannabinoid receptor type 1 decreases glutamatergic and GABAergic synaptic transmission in the lateral amygdala of the mouse. Learn Mem 10: 116-128.

Beltramo M, Rodriguez de Fonseca F, Navarro M, Calignano A, Gorriti MA, Grammatikopoulos G et al (2000). Reversal of dopamine D2-receptor responses by an anandamide transport inhibitor. J Neurosci 20: 3401-3407.

Beltramo M, Stella N, Calignano A, Lin SY, Makriyannis A, Piomelli D (1997). Functional role of high-affinity anandamide transport, as revealed by selective inhibition. Science 277: 1094-1097.

Bouton ME, King DA (1983). Contextual control of the extinction of conditioned fear: tests for the associative value of the context. J Exp Psychol Anim Behav Process 9: 248-265.

Cannich A, Wotjak CT, Kamprath K, Hermann H, Lutz B, Marsicano G (2004). CB1 cannabinoid receptors modulate kinase and phosphatase activity during extinction of conditioned fear in mice. Learn Mem 11: 625-632.

Cassella JV, Davis M (1986). The design and calibration of a startle measurement system. Physiol Behav 36: 377-383.

Chevaleyre V, Castillo PE (2003). Heterosynaptic LTD of hippocampal GABAergic synapses: a novel role of endocannabinoids in regulating excitability. Neuron 38: 461-472.

Coutts AA, Anavi-Goffer S, Ross RA, MacEwan DJ, Mackie K, Pertwee RG et al (2001). Agonist-induced internalization and trafficking of cannabinoid $\mathrm{CB} 1$ receptors in hippocampal neurons. J Neurosci 21: 2425-2433.

Cravatt BF, Demarest K, Patricelli MP, Bracey MH, Giang DK, Martin BR et al (2001). Supersensitivity to anandamide and enhanced endogenous cannabinoid signaling in mice lacking fatty acid amide hydrolase. Proc Natl Acad Sci USA 98: 9371-9376.

Davis M, Walker DL, Myers KM (2003). Role of the amygdala in fear extinction measured with potentiated startle. Ann NY Acad Sci 985: 218-232.

Falls WA, Miserendino MJ, Davis M (1992). Extinction of fearpotentiated startle: blockade by infusion of an NMDA antagonist into the amygdala. J Neurosci 12: 854-863.
Fegley D, Kathuria S, Mercier R, Li C, Goutopoulos A, Makriyannis A et al (2004). Anandamide transport is independent of fattyacid amide hydrolase activity and is blocked by the hydrolysisresistant inhibitor AM1172. Proc Natl Acad Sci USA 101: 8756-8761.

Freund TF, Katona I, Piomelli D (2003). Role of endogenous cannabinoids in synaptic signaling. Physiol Rev 83: 1017-1066.

Giang DK, Cravatt BF (1997). Molecular characterization of human and mouse fatty acid amide hydrolases. Proc Natl Acad Sci USA 94: 2238-2242.

Giuffrida A, Beltramo M, Piomelli D (2001). Mechanisms of endocannabinoid inactivation: biochemistry and pharmacology. J Pharmacol Exp Ther 298: 7-14.

Haller J, Bakos N, Szirmay M, Ledent C, Freund TF (2002). The effects of genetic and pharmacological blockade of the CB1 cannabinoid receptor on anxiety. Eur J Neurosci 16: 1395-1398.

Haller J, Varga B, Ledent C, Barna I, Freund TF (2004a). Contextdependent effects of $\mathrm{CB} 1$ cannabinoid gene disruption on anxiety-like and social behaviour in mice. Eur J Neurosci 19: 1906-1912.

Haller J, Varga B, Ledent C, Freund TF (2004b). CB1 cannabinoid receptors mediate anxiolytic effects: convergent genetic and pharmacological evidence with CB1-specific agents. Behav Pharm 15: 299-304.

Herzberg U, Eliav E, Bennett GJ, Kopin IJ (1997). The analgesic effects of $\mathrm{R}(+)$-WIN 55, 212-2 mesylate, a high affinity cannabinoid agonist, in a rat model of neuropathic pain. Neurosci Lett 22: 157-160.

Hsieh C, Brown S, Derleth C, Mackie K (1999). Internalization and recycling of the CB1 cannabinoid receptor. J Neurochem 73: 493-501.

Jarrahian A, Manna S, Edgemond WS, Campbell WB, Hillard CJ (2000). Structure-activity relationships among $\mathrm{N}$-arachidonylethanolamine (anandamide) head group analogues for the anandamide transporter. J Neurochem 74: 2597-2606.

Kathuria S, Gaetani S, Fegley D, Valino F, Duranti A, Tontini A et al (2003). Modulation of anxiety through blockade of anandamide hydrolysis. Nat Med 9: 76-81.

Katona I, Rancz EA, Acsady L, Ledent C, Mackie K, Hajos N et al (2001). Distribution of CB1 cannabinoid receptors in the amygdala and their role in the control of GABAergic transmission. J Neurosci 21: 9506-9518.

Katona I, Sperlagh B, Magloczky Z, Santha E, Kofalvi A, Czirjak S et al (2000). GABAergic interneurons are the targets of cannabinoid actions in the human hippocampus. Neuroscience 100: 797-804.

Katona I, Sperlagh B, Sik A, Kafalvi A, Vizi ES, Mackie K et al (1999). Presynaptically located CB1 cannabinoid receptors regulate GABA release from axon terminals of specific hippocampal interneurons. J Neurosci 19: 4544-4558.

Ledgerwood L, Richardson R, Cranney J (2003). Effects of Dcycloserine on extinction of conditioned freezing. Behav Neurosci 117: 341-349.

Ledgerwood L, Richardson R, Cranney J (2004). D-Cycloserine and the facilitation of extinction of conditioned fear: consequences for reinstatement. Behav Neurosci 118: 505-513.

Lin CH, Yeh SH, Leu TH, Chang WC, Wang ST, Gean PW (2003a). Identification of calcineurin as a key signal in the extinction of fear memory. J Neurosci 23: 1574-1579.

Lin CH, Yeh SH, Lu HY, Gean PW (2003b). The similarities and diversities of signal pathways leading to consolidation of conditioning and consolidation of extinction of fear memory. J Neurosci 23: 8310-8317.

Lu KT, Walker DL, Davis M (2001). Mitogen-activated protein kinase cascade in the basolateral nucleus of amygdala is involved in extinction of fear-potentiated startle. J Neurosci 21: RC162.

Marsicano G, Lutz B (1999). Expression of the cannabinoid receptor $\mathrm{CB} 1$ in distinct neuronal subpopulations in the adult mouse forebrain. Eur J Neurosci 11: 4213-4225. 
Marsicano G, Wotjak CT, Azad SC, Bisogno T, Rammes G, Cascio MG et al (2002). The endogenous cannabinoid system controls extinction of aversive memories. Nature 418: 530-534.

Martin M, Ledent C, Parmentier M, Maldonado R, Valverde O (2002). Involvement of CB1 cannabinoid receptors in emotional behaviour. Psychopharmacology (Berl) 159: 379-387.

Mato S, Chevaleyre V, Robbe D, Pazos A, Castillo PE, Manzoni OJ (2004). A single in-vivo exposure to delta 9THC blocks endocannabinoid-mediated synaptic plasticity. Nat Neurosci 7: 585-586.

McDonald AJ, Mascagni F (2001). Localization of the CB1 type cannabinoid receptor in the rat basolateral amygdala: high concentrations in a subpopulation of cholecystokinin-containing interneurons. Neuroscience 107: 641-652.

Myers KM, Davis M (2002). Behavioral and neural analysis of extinction. Neuron 36: 567-584.

Porter AC, Felder CC (2001). The endocannabinoid nervous system: unique opportunities for therapeutic intervention. Pharmacol Ther 90: 45-60.

Rescorla RA, Heth CD (1975). Reinstatement of fear to an extinguished conditioned stimulus. J Exp Psychol Anim Behav Process 1: 88-96.

Ressler KJ, Paschall G, Zhou XL, Davis M (2002). Regulation of synaptic plasticity genes during consolidation of fear conditioning. J Neurosci 22: 7892-7902.

Ressler KJ, Rothbaum BO, Tannenbaum L, Anderson P, Graap K, Zimand $\mathrm{E}$ et al (2004). Cognitive enhancers as adjuncts to psychotherapy: use of D-cycloserine in phobic individuals to facilitate extinction of fear. Arch Gen Psychiatry 61: 1136-1144.

Rothbaum BO, Davis M (2003). Applying learning principles to the treatment of post-trauma reactions. Ann NY Acad Sci 1008: 112-121.

Santini E, Muller RU, Quirk GJ (2001). Consolidation of extinction learning involves transfer from NMDA-independent to NMDAdependent memory. J Neurosci 21: 9009-9017.

Sjostrom PJ, Turrigiano GG, Nelson SB (2003). Neocortical LTD via coincident activation of presynaptic NMDA and cannabinoid receptors. Neuron 39: 641-654.

Smart D, Jerman JC (2000). Anandamide, an endogenous activator of the vanilloid receptor. Trends Pharmacol Sci 21: 134.

Suzuki A, Josselyn SA, Frankland PW, Masushige S, Silva AJ, Kida $S$ (2004). Memory reconsolidation and extinction have distinct temporal and biochemical signatures. J Neurosci 24: 4787-4795.

Tsou K, Lowitz K, Hohmann AG, Martin WJ, Hathaway CB, Bereiter DA et al (1996). Suppression of noxious stimulus-evoked expression of fos protein-like immunoreactivity in rat spinal cord by a selective cannabinoid agonist. Neuroscience 70: 791-798.

van der Stelt M, Di Marzo V (2003). The endocannabinoid system in the basal ganglia and in the mesolimbic reward system: implications for neurological and psychiatric disorders. Eur J Pharmacol 480: 133-150.

Walker DL, Ressler KJ, Lu KT, Davis M (2002). Facilitation of conditioned fear extinction by systemic administration or intraamygdala infusions of D-cycloserine as assessed with fearpotentiated startle in rats. J Neurosci 22: 2343-2351. 